Published in "Journal of Vertebrate Paleontology 38 (3): e1474886, 2018"

which should be cited to refer to this work.

\title{
A DESCRIPTION OF THE SKULL OF EUBAENA CEPHALICA (HAY, 1904) AND NEW INSIGHTS INTO THE CRANIAL CIRCULATION AND INNERVATION OF BAENID TURTLES
}

\author{
YANN ROLLOT, (D) *,1,2 TYLER R. LYSON, (iD ${ }^{3}$ and WALTER G. JOYCE (iD ${ }^{4}$ \\ ${ }^{1}$ Laboratoire Paléontologie Evolution Paléoécosystèmes Paléoprimatologie, University of Poitiers, 6 rue Michel Brunet, 86073 \\ Poitiers, France; \\ ${ }^{2}$ Institut des Sciences de l'Evolution de Montpellier, University of Montpellier, Place Eugène Bataillon, 34095 Montpellier, France, \\ yann.rollot@gmail.com; \\ ${ }^{3}$ Department of Earth Sciences, Denver Museum of Nature and Science, 2001 Colorado Boulevard, Denver, Colorado 80205, U.S.A., \\ tyler.lyson@dmns.org; \\ ${ }^{4}$ Department of Geosciences, University of Fribourg, Chemin du Musée 6, 1700 Fribourg, Switzerland, walter.joyce@unifr.ch
}

\begin{abstract}
The internal carotid system has played an important role in the systematics of fossil turtles, including baenids. A new, almost perfectly preserved specimen of Eubaena cephalica provides an opportunity to explore for the first time the cranial circulation and innervation of this taxon using CT (computed tomography) scans. We here document that the skull possesses a well-developed, branching canalis nervus vidianus but lacks a canalis caroticus palatinum, which contradicts the previously reported circulation and innervation pattern for E. cephalica specifically and that of paracryptodires in general. Future investigation using CT scanning technology will be able to clarify if the pattern reported herein is unique to E. cephalica or is representative of paracryptodires in general. The latter conclusion will likely have considerable implications for the systematics of fossil turtles.
\end{abstract}

\section{INTRODUCTION}

Baenidae Cope, 1873 , is a clade of paracryptodiran turtles that includes all species more closely related to Baena arenosa Leidy, 1870, from the Eocene of North America than Pleurosternon bullockii (Owen, 1842) from the Upper Jurassic of England (Lyson and Joyce, 2011). Following this definition, the clade consists of an assemblage of freshwater turtles endemic to North America that persisted from the Early Cretaceous to the Eocene (Hay, 1908; Gaffney, 1972a; Joyce and Lyson, 2015). Cranial remains of baenids are relatively common in the fossil record because their skulls are relatively large, thick-boned, and tightly sutured. The cranial anatomy of the group has therefore been documented in detail for a series of species (Gaffney and Hiatt, 1971; Gaffney, 1972a, 1982; Archibald and Hutchison, 1979; Brinkman and Nicholls, 1991; Brinkman, 2003; Hutchison, 2004; Lyson and Joyce, 2009a, 2009b, 2010; Lively, 2015). A baenid that has received a disproportionate amount of attention in this regard is Eubaena cephalica Hay, 1904, from the Upper Cretaceous (Maastrichtian) Lance Formation of Wyoming because it is based on a beautifully preserved skull. Whereas the holotype has been repeatedly figured (Hay, 1904, 1908; Gaffney and Hiatt, 1971; Gaffney, 1972a, 1975, 1979, 1982) and described (Hay, 1904, 1908) over the course of the last century, current insights into cranial circulation and innervation patterns in baenid turtles are based on partial skulls referred to this species (Gaffney, 1975, 1982). Whereas the holotype of Eubaena cephalica is now considered lost (Joyce and Lyson, 2015), rich new finds of

*Corresponding author. baenids from the Upper Cretaceous of North America (e.g., Lyson and Joyce 2009a, 2009b, 2010; Lyson et al., 2011) question the assignment of the fragmentary material to this species. A reassessment is therefore overdue.

We here present a newly discovered skull (DMNH 96004) from the Upper Cretaceous (Maastrichtian) Hell Creek Formation of North Dakota, U.S.A., that is virtually identical to the holotype of Eubaena cephalica in its morphology and quality of preservation. The new specimen provides an opportunity to reassess the cranial morphology of Eubaena cephalica and, more importantly, to explore for the first time the cranial circulation and innervation of a fully preserved baenid skull using CT scans.

Institutional Abbreviations-DMNH, Denver Museum of Nature and Science, Denver, Colorado, U.S.A.; YPM, Yale Peabody Museum of Natural History, New Haven, Connecticut, U.S.A.

\section{GEOLOGICAL SETTING}

Specimen DMNH 96004 was collected in 2009 at the 'Big Turtle Cove' locality (DMNH locality 6303) just northwest of the town of Marmarth in Slope County, North Dakota, U.S.A. The locality is situated at the base of the Upper Cretaceous (Maastrichtian) Hell Creek Formation, 68-70m below the locally exposed Fort Union Formation. The specimen was preserved in a soft sandstone bed rich in rip-up clasts and was found with at least one other baenid skeleton, a disarticulated macrobaenid shell, several skeletons of the giant softshell turtle Axestemys splendida (Vitek, 2012), and elements of Champsosaurus spp. and Thescelosaurus sp. More detailed locality information is on file at DMNH. The now lost holotype of Eubaena cephalica was 
collected further to the south from an unknown location in the Upper Cretaceous (Maastrichtian) Lance Formation of what is now likely Niobrara County, Wyoming, U.S.A. (Hay, 1908; Gaffney, 1972a). Both DMNH 96004 and the type skull are therefore Maastrichtian in age but were collected from two different, albeit related, basins.

\section{METHODS}

Specimen DMNH 96004 was prepared using standard paleontological techniques to expose its external anatomy. To obtain the internal anatomy, the specimen was further subjected to high-resolution X-ray micro-computed tomography using a Bruker Skyscan 2211 at the University of Fribourg, Switzerland, with 1800 projections over $360^{\circ}$, an exposure time of $0.25 \mathrm{~s}$, a voltage of $180 \mathrm{kV}$, and a current of $78 \mu \mathrm{A}$, which were converted into 1801 coronal slices with a voxel size of $37 \mu \mathrm{m}$. Virtual threedimensional bones and canals were generated and visualized using the Thermo Scientific Amira software (6.1.1). All reconstructions were obtained through slice-by-slice segmentation followed by production of isosurface models. Whereas the boundaries of each bone were delimited manually using the brush and lasso tools of Amira, canals also were partially segmented using the interpolate tool.

\section{NOMENCLATURE}

We herein generally follow the cranial nomenclature proposed by Gaffney (1972b), with the modifications to the carotid system proposed by Rabi et al. (2013). Because the vidian canal system consists of up to three different canals, we here present a new nomenclature for the two canals existing in baenid turtles. Future work on pleurodires may require addition of supplementary terms for the passage of the hyomandibular nerve.

Canalis pro Ramo Nervi Vidiani-The canal connecting the sulcus cavernosus to the ventral side of the skull or the canalis caroticus internus. The canal contains the palatal ( = vidian) branch of the facial nerve and is mostly located within the prootic (Gaffney, 1979).

Foramen Proximalis Nervi Vidiani-The laterally positioned entry into the canalis pro ramo nervi vidiani. This foramen is typically not visible in ventral view.

Foramen Distalis Nervi Vidiani-The medially positioned exit of the canalis pro ramo nervi vidiani onto the ventral surface of the skull or into the canalis caroticus internus.

Canalis Nervus Vidianus-The anteroposteriorly oriented canal that transmits the vidian nerve towards the front of the skull. The canal is mostly located within the pterygoid.

Foramen Posterius Canalis Nervi Vidiani-The posterior entry into the canalis nervus vidianus on the ventral side of the pterygoid. This foramen is often located within the canalis caroticus internus and, therefore, may not be visible in ventral view.

Foramen Anterius Canalis Nervi Vidiani-The anterior exit of the canalis nervus vidianus. The foramen is typically located posteromedially to the orbit and may be split into multiple foramina that exit in a row onto the ventral or dorsal side of the pterygoid. Bones adjacent to the pterygoid, in particular the palatine and the parietal, may also form the margins of the most distally located exits.

\section{SYSTEMATIC PALEONTOLOGY \\ TESTUDINES Batsch, 1788 \\ CRYPTODIRA Cope, 1868 \\ PARACRYPTODIRA Gaffney, 1975 \\ BAENIDAE Cope, 1873 \\ EUBAENA CEPHALICA (Hay, 1904)}

(Figs. 1-3)
Type Specimen-YPM 1785 (holotype, now lost), a cranium (Hay, 1904:pl. 12, 1908:pls. 19.4, 21.1, 2; Gaffney and Hiatt, 1971: fig. 5; Gaffney, 1972a:figs. 18, 19, 57).

Type Locality-Niobrara County, Wyoming, U.S.A. (Hay, 1908; Gaffney, 1972a); Lance Formation, Maastrichtian, Late Cretaceous (Gaffney, 1972a). Converse County was split into two counties in 1911, yielding Converse County to the west and Niobrara County to the east. We here conclude that the type locality is located in modern day Niobrara County, because the town of Lance Creek and the Lance Creek drainage are both located there.

Referred Material-DMNH 96004, a near complete cranium, Late Cretaceous (Maastrichtian), Hell Creek Formation of North Dakota.

Diagnosis-Eubaena cephalica can be diagnosed as a member of Paracryptodira based on the location of the foramen posterius canalis carotici interni halfway along the pterygoid-basisphenoid suture, as a member of Baenidae based on the presence of a wedge-shaped skull and a well-developed pterygoid-basioccipital contact, and as a member of Baenodda based on the presence of reduced nasals and prefrontals, loss of the parietal-squamosal contact, and exclusion of the opisthotic from the foramen stapedio-temporale. Eubaena cephalica can be differentiated from other baenodds based on the presence of open sutures in the skull of skeletally mature individuals, presence of an incipient secondary palate, exclusion of the jugal from the margin of the orbit, small orbits, broadly expanded posterior triturating surfaces, swollen maxillae, and an elongate snout.

\section{DESCRIPTION}

Skull-The skull (Figs. 1,2) is generally well preserved but shows minor crushing in the anteromedial part of the orbit and anterior extension of the braincase (Fig. 2A). The skull is wedge-shaped and moderately large for a baenid, with a midline length of $76.5 \mathrm{~mm}$ and a maximum width of $62.8 \mathrm{~mm}$. The majority of sutures can be observed with ease, but scute sulci are only apparent in parts of the dorsal skull roof (Fig. 1). The upper temporal emargination is deep, and the otic chamber and its anterior margin are therefore visible in dorsal view. The cheek emargination, on the other hand, only intrudes the skull to the level of the lower margin of the orbit. The supraoccipital crest barely projects beyond the level of the foramen magnum. The orbits are widely spaced and oriented dorsolaterally.

Nasals-The nasals (Fig. 1A, C) are relatively large, almost circular bones. In dorsal view, the nasals contact each other anteromedially along their anterior halves, but their posterior halves are separated from one another by an extension of the frontals. At their posterior margin, the nasals are slightly covered by the frontals along a convex suture. The nasals contact the maxillae laterally along a straight suture. In ventral view, the nasals are roughly triangular, form the dorsal margin of the apertura narium externa, and roof the anterodorsal part of the fossa nasalis. At their anterior margins the nasals jointly form a small, ventrally curved hook best seen in anterior view (Fig. 1C). The nasals contact each other along a groove within the nasal cavity. The anterior processes of the frontals that separate the nasals in dorsal view also contact the nasals at the top of the groove within the nasal cavity, thereby preventing the nasals from contacting each other for the rest of their posterior extension. Within the nasal cavity, the nasals have a minor posterolateral contact with the prefrontals. The nasals terminate posteriorly within the nasal cavity at the level of the anterior margin of the fossa orbitalis.

Prefrontals-The prefrontals (Fig. 1A, C, E) form the anterior quarter of the roof of the orbit, but with the exception of a minor sliver along the anterodorsal margin of the orbit, the dorsal plate of the prefrontals is hidden from dorsal view by the surrounding 


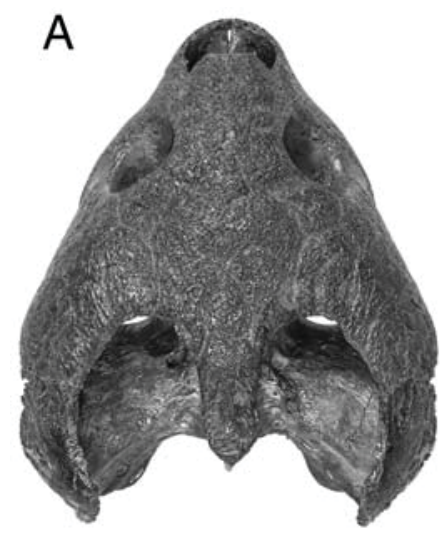

C
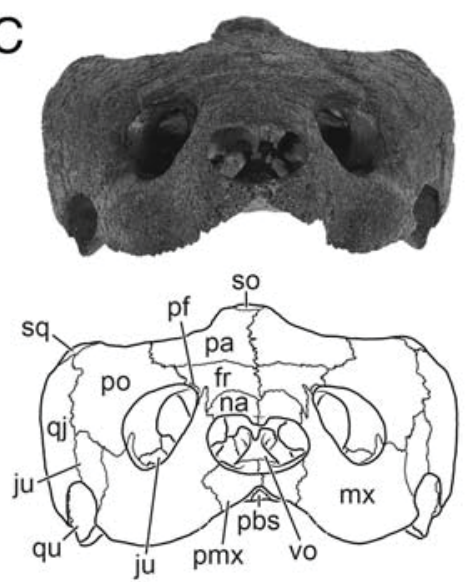

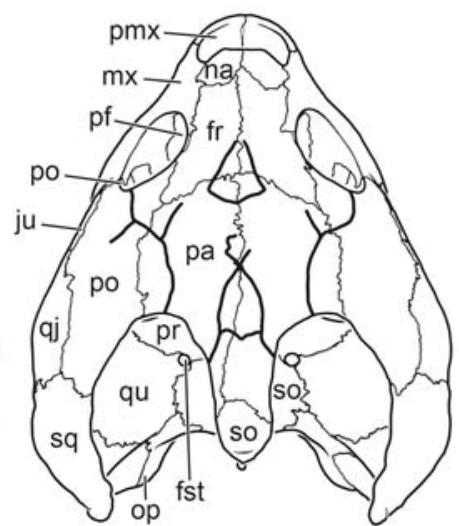

B
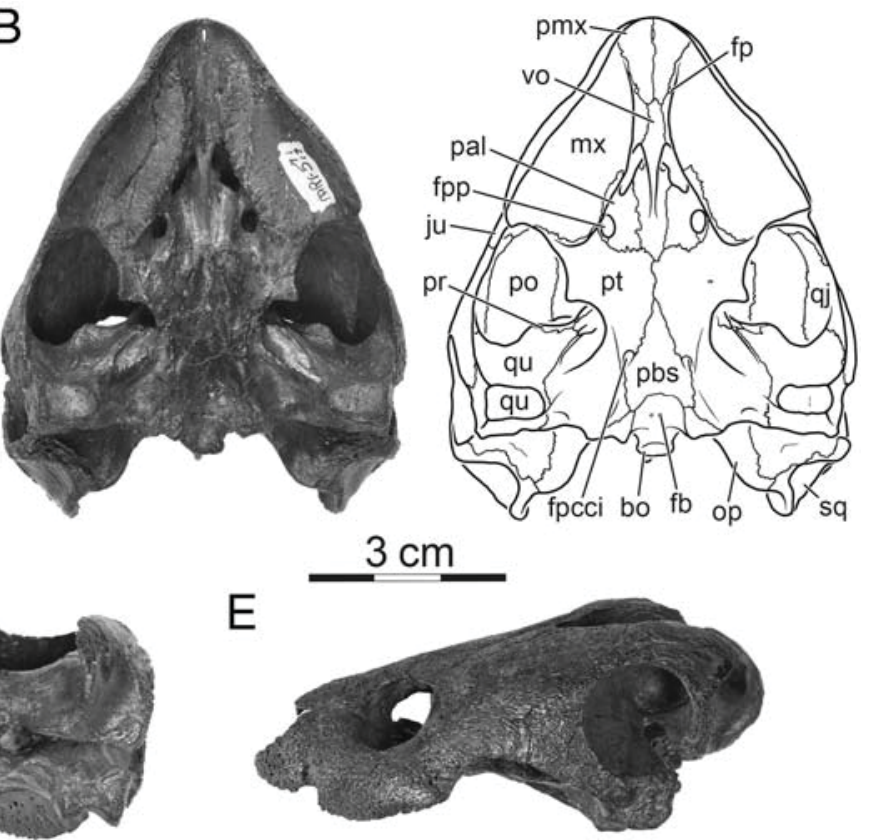

D
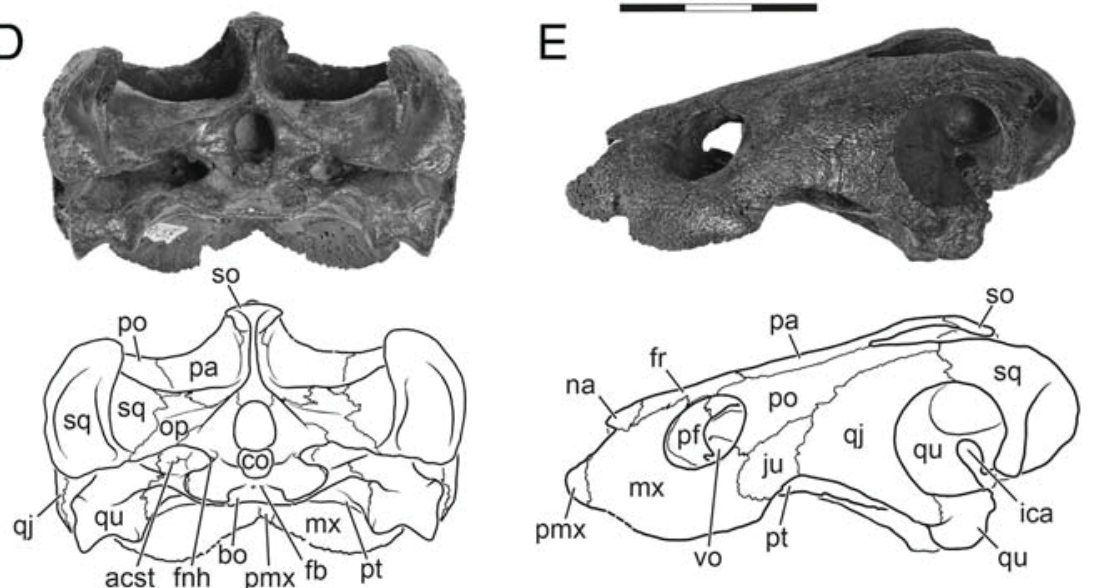

FIGURE 1. Eubaena cephalica, DMNH 96004, Upper Cretaceous (Maastrichtian) of North Dakota, U.S.A. Photographs and illustrations of skull in $\mathbf{A}$, dorsal, B, ventral, $\mathbf{C}$, anterior, D, posterior, and $\mathbf{E}$, left lateral views. Abbreviations: acst, aditus canalis stapedio-temporalis; bo, basioccipital; co, condylus occipitalis; fb, foramen basioccipitale; fnh, foramen nervi hypoglossi; $\mathbf{f p}$, foramen praepalatinum; fpeci, foramen posterior canalis carotici interni; fpp, foramen palatinum posterius; fr, frontal; fst, foramen stapedio-temporale; ica, incisura columella auris; ju, jugal; mx, maxilla; na, nasal; op, opisthotic; pa, parietal; pal, palatine; pbs, parabasisphenoid; pf, prefrontal; pmx, premaxilla; po, postorbital; pr, prootic; pt, pterygoid; qj, quadratojugal; qu, quadrate; so, supraoccipital; sq, squamosal; vo, vomer.

elements. Anteromedially, the dorsal plate is covered by the frontal, roofs the posterodorsal part of the fossa nasalis, and contacts the nasal medially and the maxilla laterally. On the surface, the dorsal plate contacts the frontal medially and posteriorly and the maxilla anterolaterally. The descending process of the prefrontals forms the fossa orbitalis anteromedially, the fossa nasalis posterolaterally, and the anterior margin of the foramen interorbitale. The medial aspect of the descending processes is broken on both sides of the skull, and the distal contact with the vomer is therefore not preserved. However, the preserved articulation sites on the vomer indicate that the prefrontal-vomer contact must have been substantial. The descending process contacts the palatine posteroventrally and frames the anterior margin of the elongate foramen orbito-nasale.

Frontals-The frontals (Fig. 1A, C, E) are anteroposteriorly elongated, almost rectangular bones that are slightly broader posteriorly than anteriorly. The frontals meet each other along the midline and contact the nasals anteriorly, the maxillae anterolaterally, the dorsal plate of the prefrontals laterally, the postorbitals posterolaterally, and the parietals posteriorly. The suture between the frontals is clearly visible in dorsal view but remains unclear ventrally. The frontals contribute to the margin of the orbit and thereby prevent the prefrontals and the postorbitals from contacting each other. The frontals roof the dorsomedial part of the fossa orbitalis and form a ridge together with the prefrontals and parietals that separates the orbital cavity from the olfactory sulcus.

Parietals-The parietals (Fig. 1A, C-E) are paired bones that are approximately twice as long as wide and form the posterior part of the skull roof. The parietals are composed of two plates: a dorsal one and a vertical one. Whereas the dorsal plate roofs the braincase, the vertical plate, or processus inferior parietalis, forms the anterior extension of the lateral wall of the braincase (Fig. 2A-C), the posterior margin of the foramen interorbitale, and the medial border of the fossa temporalis. The dorsal plate forms the anteromedial margin of the upper temporal emargination and contacts the frontals anteriorly, the postorbital laterally, the supraoccipital posteriorly, and the dorsal plate of the other parietal medially. The descending branch of the parietals is developed along the entire length of the bone, but its distal portions are partially damaged and therefore cannot be assessed with full confidence (Fig. 2A-C). A distinct groove is visible on the ventral side of the anterior portion of the processus inferior parietalis. The descending process expands distally to articulate with the palatine and to form the dorsal roof of the foramen anterius canalis nervi vidiani. The distal contact with the pterygoid is mostly damaged, but it appears to have been less thickened distally. Further posteriorly, the descending process overlaps the prootic slightly and forms a thin process that roofs the trigeminal foramen and that contacts the pterygoid a second 


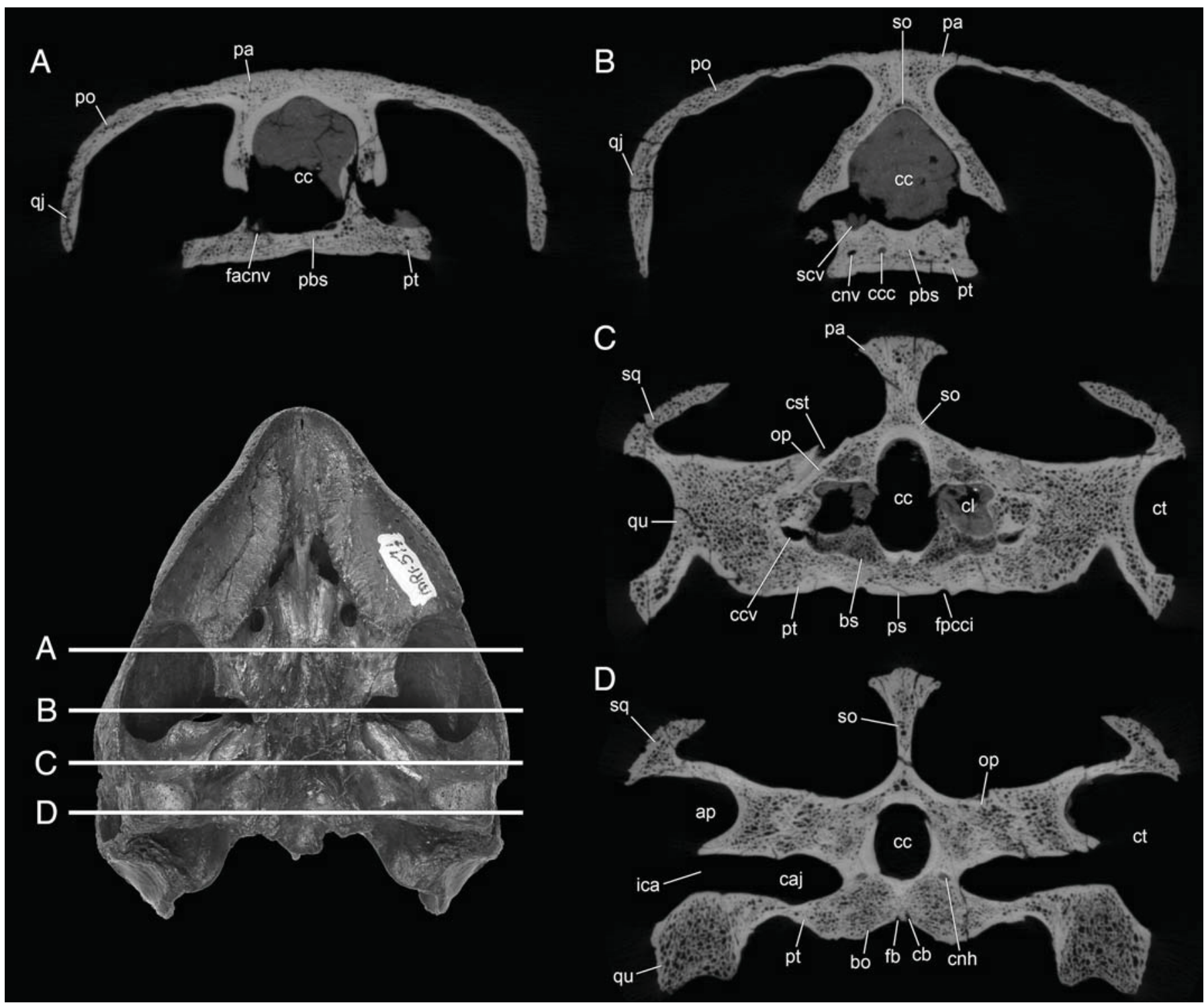

FIGURE 2. Coronal cross-sections of DMNH 96004, Eubaena cephalica, Upper Cretaceous (Maastrichtian) of North Dakota, U.S.A. A, anterior section showing minor crushing to the skull along the anterior wall of the braincase and the foramen anterius canalis nervi vidiani. B, a more posterior section showing the canalis nervus vidianus and the canalis caroticus internus. $\mathbf{C}$, section showing the parasphenoid, the basisphenoid, and the foramen posterius canalis carotici interni. D, posterior section showing the canalis basioccipitalis and the foramen basioccipitale. Abbreviations: ap, antrum postoticum; bo, basioccipital; bs, basisphenoid; caj, cavum acustico-jugulare; $\mathbf{c b}$, canalis basioccipitalis; $\mathbf{c c}$, cavum cranii; ccc, canalis caroticus cerebralis; ccv, canalis cavernosus; cl, cavum labyrinthicum; cnh, canalis nervi hypoglossi; cnv, canalis nervus vidianus; cst, canalis stapedio-temporale; ct, cavum tympani; facnv, foramen anterius canalis nervi vidiani; $\mathbf{f b}$, foramen basioccipitale; fpcci, foramen posterius canalis carotici interni; ica, incisura columella auris; op, opisthotic; pa, parietal; pal, palatine; pbs, parabasisphenoid; po, postorbital; ps, parasphenoid; pt, pterygoid; qj, quadratojugal; qu, quadrate; scv, sulcus cavernosus; so, supraoccipital; sq, squamosal.

time posterior to the trigeminal foramen. The processus inferior parietalis contacts the supraoccipital posterodorsally.

Postorbitals-The postorbitals (Fig. 1A, C-E) are elongated, plate-like bones that form the lateral aspects of the dorsal skull roof. The postorbitals form the posterior margins of the fossa orbitalis and form a thickened descending process that forms the posterior wall of the orbit. Although it seems clear that the descending process contacts the pterygoid within the orbit, damage obscures a likely distal contact with the maxilla. The postorbitals have a strongly interlocked suture with the maxillae along the margin of the orbit, contact the frontals anteriorly, and have an overlapping, convex suture with the parietals medially. The postorbitals contact the jugals ventrolaterally on the surface of the skull and, separately, within the orbit. The postorbitals otherwise contact the quadratojugal posteroventrolaterally and the squamosals posterolaterally and form the anterior limit of the upper temporal emargination posteriorly.

Jugals-The jugals (Fig. 1A-C, E) are small, paired bones, exposed laterally in the cheek region and within the orbit. The jugals form the posteroventrolateral part of the fossa orbitalis and the anterodorsal limit of the lower temporal emargination. Inside the fossa orbitalis, the jugals broadly lap onto the maxilla anteriorly, contact the postorbital posteriorly, and frame the lateral aspects of the foramen supramaxillare, but a possible, small contact with the pterygoid is obscured by damage on both sides of the skull. A clear contact with the pterygoid is apparent along the anterior margin of the lower temporal emargination. On the surface of the skull, the jugals 


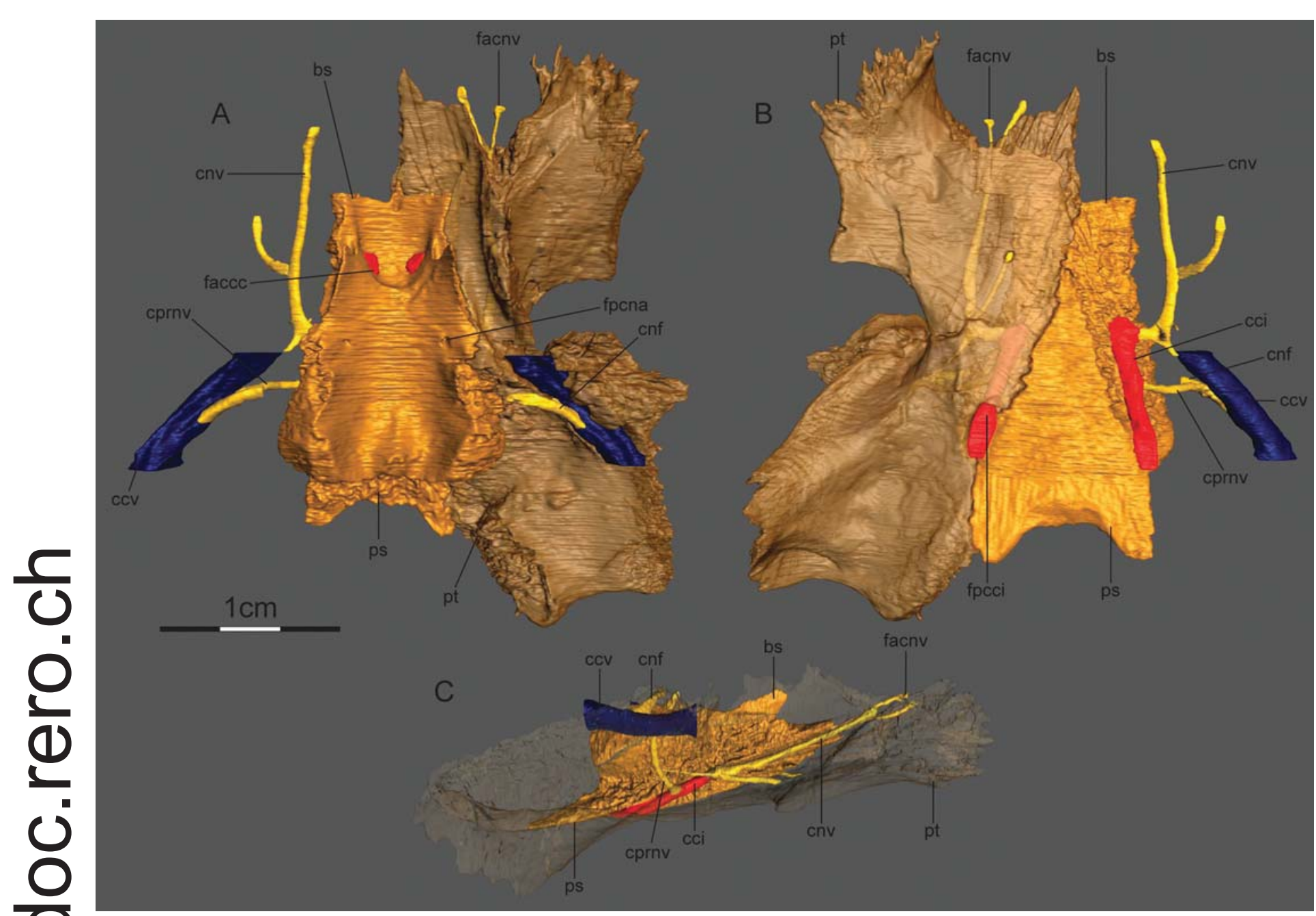

FIGURE 3. Three-dimensional reconstructions of the parabasisphenoid, right pterygoid, carotid circulation, and vidian canal system of DMNH 96004. The canalis cavernosus is highlighted in blue, the carotid system in red, and the vidian system in yellow. The pterygoid is rendered partially transparent to allow discerning the path of the canals within the bone. $\mathbf{A}$, dorsal, $\mathbf{B}$, ventral, and $\mathbf{C}$ right lateral views. Abbreviations: bs, basisphenoid; cci, canalis caroticus internus; cev, canalis cavernosus; cnf, canalis nervus facialis; cnv, canalis nervus vidianus; cprnv, canalis pro ramo nervi vidiani; facce, foramen anterius canalis carotici cerebralis; facnv, foramen anterius canalis nervi vidiani; fpcci, foramen posterius canalis carotici interni; fpena, foramen posterius canalis nervi abducentis; ps, parasphenoid; pt, pterygoid.

contact the maxilla anteriorly, the postorbital ventrally, and the quadratojugal posteriorly.

Quadratojugals-The quadratojugals (Fig. 1) are thin, 'C'shaped bones. In lateral view, the quadratojugals form the posterior part of the cheek emargination, contact the jugal anteriorly, the postorbital dorsally, and the squamosal posteriorly, and contact the quadrate posteriorly along the anterior rim of the cavum tympani. The quadratojugals are overlapped partially by the jugals. A contribution to the upper temporal emargination is clearly prevented by a broad contact of the postorbital with the squamosal.

Squamosals-The squamosals (Fig. 1) form the posterodorsal limit of the skull, the posterodorsal parts of the antrum postoticum, the posterior rim of the cavum tympani, and the lateral margin of the upper temporal emargination. In lateral view, the squamosals contact the postorbital anterodorsally and the quadratojugal anteroventrally above the cavum tympani. Within the cavum tympani and the antrum postoticum, the squamosals overlap the quadrate medially to form an almost horizontal suture. Within the temporal fossa, the squamosals form a thin sheet of bone that overlaps the quadrate anteromedially and the opisthotic posteromedially. The posterior part of the antrum postoticum is entirely bordered by the squamosals.

Premaxillae-The premaxillae (Fig. 1A-C, E) floor the anteroventral portions of the fossa nasalis and form the ventral margin of the apertura narium externa. The premaxillae bear the anterior portion of the sharp labial ridge, which is lower than the portions formed by the maxillae. In ventral and dorsal views, the premaxillae contact the maxillae laterally, form the anterior and lateral rim of the foramen praepalatinum, and contact the vomer posteriorly. The premaxillae form a rounded ridge along their medial suture that constricts the nasal cavity from below and forms the median tongue groove from below. A small opening of unknown function is visible along the medial suture of the two premaxillae.

Maxillae-The maxillae (Fig. 1) form the anteroventral portion of the snout. In ventral view, the maxillae contact the premaxilla anteromedially, the vomer medially anterior to the apertura narium interna, the palatine posteromedially anterolateral to the foramen palatinum posterius, the pterygoid posteromedially posterolateral to the foramen palatinum posterius, and the pterygoid posteromedially and the jugal posterolaterally at 
the margin of the lower temporal fossa. The maxillae form, together with minor contributions from the palatines and the pterygoids, a broad, flat triturating surface that is laterally bordered by distinct labial ridges. Only minor crenulations define the medial aspects of the triturating surface. Accessory ridges are lacking completely. The ascending processes of the maxillae form the lateral margin of the apertura narium externa and contact the nasal anteromedially, the frontal medially, and the prefrontal posteroventrally along the margin of the fossa orbitalis. Behind the fossa orbitalis, the maxillae contact the jugal posteriorly and the postorbital dorsally. The maxillae form the majority of the flooring of the fossa orbitalis. Within the fossa, the maxillae contact the prefrontal anteromedially, the jugal posteromedially, the pterygoid posteriorly, and the palatine medially and form the medial aspects of the foramen supramaxillare. A minor contact may have been present with the postorbital, but damage obscures this region.

Vomer-The vomer (Fig. 1B) is a single, narrow bone. In ventral view, the vomer has a brief, anterior contact with the premaxilla, an elongate lateral contact with the maxilla anterior to the internal nares, an elongate lateral contact with the palatine posterior to the internal nares, and a narrow posterior contact with the pterygoid, which prevents the palatines from contacting each other medially. The dorsolateral contact of the vomer with the prefrontal is not preserved but can be inferred to have been substantial based on well-developed articular sites preserved on the vomer. The vomer forms the medial border of the apertura narium interna and posteromedially floors the fossa nasalis. A deep median groove extends along the posterodorsal part of the vomer, the sulcus vomeri.

Palatines-The palatines (Fig. 1B) are plate-like bones that form the posterior portions of the nasal passages together with the vomer. The palatines form the posterior margin of the apertura narium interna, the entire foramen palatinum posterius, and the lateral rim of the foramen orbito-nasale. In ventral view, the palatines contact the vomer medially along a straight, anteroposteriorly oriented suture, the maxilla laterally between the apertura narium interna and the foramen palatinum posterius, and the pterygoid posteriorly. At the level of the contact between the maxilla and the palatine, each palatine contributes a little to the triturating surface and the low, crenulated ridge that ornaments it medially. Within the orbit, the palatine contacts the descending process of the prefrontal anterodorsally, the premaxilla anterolaterally, and the jugal laterally. The palatines contact the descending process of the parietal dorsally behind the orbit and form the ventral margin of the foramen anterius canalis nervi vidiani.

Pterygoids-The pterygoids (Figs. 1B, D, E, 3A-C) are elongated bones most apparent in palatal view. The pterygoids form the lateral margin of the foramen posterius canalis carotici interni, which is situated about halfway along the length of the pterygoid-basisphenoid suture. In palatal view, the anterior half of the pterygoids have a straight anterior suture with the palatine, an anteromedial contact with the vomer, an anterolateral contact with the maxilla at the posteromedial limit of the lingual ridge, and an anteromedial contact with the jugal at the anteromedial margin of the lower temporal fenestra. The posterior half of the pterygoids floors the cavum acustico-jugulare and has a long medial suture with the basisphenoid, a short, posteromedial contact with the basioccipital-exoccipital complex, and a long, posterolateral contact with the quadrate that originates posterior to the foramen nervi trigemini and ends posteromedially to the condylus mandibularis. The pterygoids form the ventral floor of the confluent fenestra postotica. The pterygoids bear a welldeveloped processus pterygoideus that protrudes deeply into the temporal fossa and is decorated by a small, vertical flange. Within the fossa orbitalis, the pterygoids clearly contact the descending process of the postorbital, but a small possible contact with the jugal is not preserved due to localized crushing. The pterygoids form a short, plate-like dorsal extension that covers the palatines dorsally in this region, and which in return is covered by the plate-like rostrum basisphenoidale. The crista pterygoidea anteriorly contacts the descending process of the parietal, forms the ventral margin of the trigeminal foramen, posteriorly forms the posterior margin of the trigeminal foramen and contacts the quadrate, and posterodorsally contacts the prootic and, once again, the distal end of the descending process of the parietal. We interpret a deep, rounded groove below the trigeminal foramen as the fossa cartilaginis epipterygoidei, a remnant of the unossified palatoquadrate cartilage, which normally ossifies as the epipterygoid. The pterygoids form the lateral wall of the internal carotid artery from the foramen posterius canalis carotici interni until its split into the canalis caroticus cerebralis and the canalis nervus vidianus. Anterior to that bifurcation point, the vidian nerve is located within the pterygoid and the carotid artery in the basisphenoid (see Canalis Caroticus Internus and Cerebralis and Discussion for alternative interpretations). The pterygoid forms the ventral margin of the sulcus cavernosus and forms the lateral margin of the foramen anterius canalis nervi abducentis.

Epipterygoids-The epipterygoids are not preserved, but localized crushing makes it difficult to discern with full confidence if the elements were present in the first place. A deep groove is present on both sides of the skull, just below the trigeminal foramen, that may correspond to the former location of the epipterygoid, the fossa cartilaginis epipterygoidei. The void is mostly positioned on the pterygoid, but a minor posterior extension covers the quadrate as well.

Quadrates-The quadrates (Fig. 1) are stout elements that form most of the middle ear. In lateral view, the quadrate contacts the quadratojugal anteriorly along a curved, concave suture that runs parallel to the anterior margin of the cavum tympani and the squamosal dorsally and posterodorsally inside the cavum tympani and the antrum postoticum. The quadrate forms the smooth, funnel-shaped cavum tympani and all medial aspects pertaining to antrum postoticum but does not form the lateral margin of the antrum postoticum. Within the upper temporal fossa, the quadrate contacts the prootic anteromedially along a broad vertical suture, the quadratojugal anterolaterally, the supraoccipital medially, the opisthotic posteromedially, and the squamosal posterolaterally. The quadrate forms the posterolateral border of the foramen stapedio-temporale. In ventral view, the quadrate contacts the prootic anteromedially, the pterygoid medially, and the quadratojugal laterally. The quadrate forms the lateral half of the processus trochlearis oticum but does not contribute to the margin of the trigeminal foramen. A remnant of the unossified palatoquadrate or of the epipterygoid forms a groove in the quadrate in this region. The extension of the quadrate below the cavum tympani bears the condylus mandibularis and forms the lateral margin of the cavum acustico-jugulare, but the deeply incised incisura columella auris remains open posteriorly.

Prootics-The prootics (Fig. 1A, B) are exposed in the anteromedial part of the upper temporal fossa. In dorsal view, the prootics contact the quadrate posterolaterally, the parietal anteromedially, and the supraoccipital posteromedially, and form the medial half of the processus trochlearis oticum. The prootics form the anterior and medial margins of the foramen stapediotemporale. The canalis stapedio-temporalis rises along the prootic-quadrate suture from its origin at the canalis cavernosus, with a greater participation of the quadrate to the formation of the canal. The canalis stapedio-temporale has a greater diameter than the canalis caroticus internus. In lateral view, the prootics have an anteromedial contact with the pterygoid, and a posterolateral contact with the quadrate, and form the dorsal margin of the foramen nervi trigemini. The prootics form the lateral wall of 
the cavum cranii from the anterior level of the foramen nervi trigemini to that of the foramen stapedio-temporale. Several intracranial structures and canals are partially or fully formed by the prootics: the cavum labyrinthicum, the canalis semicircularis anterior, the canalis semicircularis horizontalis, the recessus labyrinthicus prooticus, the sulcus cavernosus, the fossa acusticofacialis, and the canals of the facial nerve (VII) and the acoustic nerve (VIII). The fossa acustico-facialis is a small, medially located depression that communicates with the cavum cranil along two foramina: the single, dorsally directed acoustic nerve canal, which leads to the ventral part of the cavum labyrinthicum, and the ventrolaterally oriented facial nerve canal, which joins the dorsomedial part of the canalis cavernosus. The prootics form the dorsal margin of the foramen cavernosum, the anterior margin of the cavum labyrinthicum, and the anterior portions of the canalis semicircularis anterior and the canalis semicircularis horizontalis.

Opisthotics-The opisthotics (Fig. 1A, B, D) are exposed on the dorsal surface of the skull within the upper temporal fossa In dorsal view, the opisthotics contact the quadrate anterolaterally, the supraoccipital anteromedially, the basioccipital-exoccipital complex posteromedially, and the squamosal posterolaterally. In posterior view, the opisthotics contact the supraoccipital dorsomedially, the quadrate dorsally, the squamosal laterally, and the exoccipital ventromedially, and form the dorsal margin of the confluent fenestra postotica. Within the roof of the cavum acustico-jugulare, the opisthotics have a long anterolateral suture with the quadrate that runs into the dorsomedial corner of the ventral opening of the canalis stapedio-temporalis and a long posterolateral suture with the exoccipital that runs dorsomedially into the foramen jugulare anterius. The processus interfenestralis is damaged on both sides of the skull, but the better-preserved right side reveals that it was a slender process with a broad base aligned with the suture of the basioccipital-exoccipital complex that may have reached the floor of the cavum acustico-jugulare, although damage obscured the relevant area. The base of the processus interfenestralis is pierced by the foramen nervi glossopharyngei, which trends parallel to the suture with the basioccipital-exoccipital complex as well. The processus interfenestralis also defines the medial aspects of the fenestra perilymphatica, which is about the size of the stapedial canal and confluent with the foramen jugulare anterius. The opisthotics surround the posterior part of the cavum labyrinthicum and form the dorsal rim of the cavum acustico-jugulare, the posterior part of the canalis semicircularis horizontalis, and the posterior part of the canalis semicircularis posterior.

Supraoccipital-The supraoccipital (Fig. 1A, C-E) is a single bone exposed on the dorsal part of the skull. The supraoccipital forms the dorsal margin of the foramen magnum, roofs the cavum cranii posteriorly and the cavum labyrinthicum posterodorsomedially, and borders the canalis semicircularis anterior posteriorly and the canalis semicircularis posterior medially. The crista supraoccipitalis is tall, but short, only protrudes a little past the foramen magnum, and slightly roofs the upper temporal fossa. The supraoccipital is exposed on the skull roof posteriorly for about one half of its total length and contacts the parietal anteriorly. Within the upper temporal fossa, the supraoccipital contacts the parietal anteriorly and dorsomedially, the prootic anterolaterally, the quadrate laterally, the opisthotic posterolaterally, and the exoccipital posteromedially and only barely contributes to the greater margin of the foramen stapediotemporale.

Basioccipital-Exoccipitals - The basioccipital and exoccipitals (Fig. 1B, D) can be distinguished neither on the surface of the skull nor in the CT scans, indicating that the skull belongs to a skeletally mature individual. We therefore discuss both bones in concert. The basioccipital-exoccipital complex forms the medial margin of the fenestra postotica, the lateral and ventral borders of the foramen magnum, and the condylus occipitalis. In posterior view, the complex contacts the supraoccipital dorsally and the opisthotic laterally. Within the cavum acustico-jugulare, the basioccipital-exoccipital complex contacts the opisthotic anterodorsolaterally and the pterygoid anteroventrolaterally and forms the lateral margin of the foramen jugulare anterius. The basioccipital-exoccipital complex encloses the two foramina nervi hypoglossi on each side medial to the fenestra postotica. The fusion between the exoccipitals and the basioccipital makes it impossible to determine their relative participation to the condylus occipitalis. In ventral view, the basioccipital-exoccipital complex contacts the basisphenoid anteriorly along a deep concave suture. In this view, the complex forms a deep, semilunate depression just behind the parabasisphenoid that is pierced by two small foramina (Figs. 1B, 2D) that lead to the cavum cranii (see Canalis Basioccipitalis below).

Parabasisphenoid-The parabasisphenoid (Figs. 1B, C, 2A-C) is a composite bone exposed on the ventral surface of the skull. A thick dorsal part with spongy bone and a thin ventral plate with denser bone make up the posterior part of the parabasisphenoid anterior to the suture with the basioccipital. We tentatively identify these as the fused homologs of the basisphenoid and the parasphenoid, respectively. In ventral view, the parasphenoid (Figs. 2C, 3A-C) extends more posteriorly than the basisphenoid and has a long lateral suture with the pterygoid and a convex suture with the basioccipital posteriorly. Below the surface of the skull, the basisphenoid (Figs. 2C, 3A-C) contacts the pterygoid anteriorly and laterally to form the medial aspects of the sulcus cavernosus and contacts the prootic dorsolaterally. The parabasisphenoid medially borders the canalis caroticus internus and fully encloses the cerebral branch of the carotid artery following its split with the vidian canal. The foramina anterius canalis carotici cerebralis are widely spaced and positioned anteroventral to the dorsum sellae. The foramen cavernosum, the large junction between the canalis cavernosus and the cavum cranii, is located anterodorsolateral to the foramen anterius canalis carotici cerebralis. The canalis nervi abducentis enters the basisphenoid dorsal to the bifurcation between the internal carotid artery and the vidian canal and exits the basisphenoid in the canalis cavernosus posteromedially to the foramen cavernosum

Cranial Scales-The presence of scale sulci on the dorsal skull roof (Fig. 1A) allows us to discern the limits of some cranial scales. A triangular scale is positioned on the middle of the skull roof midway along the suture between the parietals, reminiscent of scale X in basal turtles (Sterli and de la Fuente, 2013). Another triangular scale is located between the orbits; it covers the suture between the parietals and the frontals and resembles scale Y of basal turtles (Sterli and de la Fuente, 2013). A third, small midline scale is positioned just in front of the first, but it lacks any apparent homology. Up to four additional scales are highlighted by additional sulci: two scales along the posterior rim of the orbit, best seen on the left side, a posteromedial scale that mostly covers the parietal, and a posterolateral scale that mostly covers the postorbital. These scales may correspond to scales $\mathrm{L}$, G, and D, respectively (Sterli and de la Fuente, 2013), but all homologies phrased herein must be viewed with caution.

Canalis Caroticus Internus and Cerebralis-The canalis caroticus internus (Fig. 3) are paired canals that contain the internal carotid artery. The posterior opening of the canalis caroticus internus, the foramen posterius canalis carotici interni, is located halfway along the pterygoid-basisphenoid suture. The basisphenoid forms the medial wall of the posterior portions of the internal carotid artery and the pterygoid the lateral wall. The path of the internal carotid canal is almost straight and directed dorsomedially. Just anterior to the foramen posterius canalis carotici interni, the canalis pro ramo nervi vidiani enters the canalis caroticus internus. This entry occurs from dorsolateral, is formed by the pterygoid, and has no 
influence on the path or on the size of the canalis caroticus internus. The next bifurcation occurs at the level of the anterior end of the otic chamber where the canalis nervus vidianus exits the canalis caroticus internus laterally. Because the canalis caroticus palatinum is absent (see Discussion), we name the portion of the canalis caroticus internus located anteriorly to the split with the canalis nervus vidianus the canalis caroticus cerebralis. This split once again has no impact on the diameter of the carotid canal. The canalis caroticus cerebralis is fully located within the basisphenoid, shows no evidence of an additional split, and opens through the widely spaced foramina anterius canalis carotici cerebralis on the dorsal surface of the basisphenoid, within the sella turcica, slightly anterior to the dorsum sellae.

Canalis pro Ramo Nervi Vidiani-The canalis pro ramo nervi vidiani (Fig. 3) is a short canal that connects the canalis cavernosus dorsally to the canalis caroticus internus ventrally and transmits the palatal branch of the facial nerve (VII), which is also known as the vidian nerve. Most of the canalis pro ramo nervi vidiani is formed by the pterygoid, with the exception of the most proximal portions, which are located within the prootic.

Canalis Nervus Vidianus-The canalis nervus vidianus (Figs. 2B, 3) originates within the canalis caroticus internus, anterior to the foramen distalis nervi vidiani. It is directed anteriorly and is mostly formed by the pterygoid. Two small, short canals leave the left canalis nervus vidianus ventrally near the posterior entry and open onto the ventral surface of the pterygoid. At the level of the entry of the canalis caroticus internus into the cavum cranii, another ventrolaterally directed cana leaves the left vidian nerve canal. This canal opens onto the ventral surface of the pterygoid. A small canal splits from the right canalis nervus vidianus anteromedially at mid-distance and opens onto the ventral surface of the pterygoid. Close to the right foramen anterius canalis nervi vidiani, a second canal leaves the right canalis nervus vidianus medially and opens medially to the foramen palatinum posterius at the suture between the pterygoid and the palate. The right and left vidian canals open anteriorly through the foramina anterius canalis nervi vidiani. The foramina anterius canalis nervi vidiani are bordered by the parietal dorsally and by the palate laterally, medially, and ventrally.

Canalis Cavernosus-The canalis cavernosus (Figs. 2C, 3A-C) primarily contains the vena capitis lateralis, which it transmits from the cavum acustico-jugulare anterolaterally to the dorsolateral part of the fenestra postotica. The margin of the posterior portion of the canalis cavernosus is formed by the prootic dorsally and by the pterygoid ventrally. A round expansion of the canal is apparent midway along the canalis cavernosus towards the cavum cranii, which likely corresponds to the geniculate ganglion because it is developed at the point of entry of the facial nerve into the canalis cavernosus. At this point, the facial nerve divides into the palatal (or vidian) branch, which joins the canalis caroticus internus via the canalis pro ramo nervi vidiani, and the hyomandibular branch, which travels posteriorly inside the canalis cavernosus. Anterior to the geniculate ganglion, the canalis cavernosus is bordered dorsomedially by the prootic and ventrally and laterally by the pterygoid. The point where the canalis cavernosus enters the cavum cranii is the foramen cavernosum, which separates the canalis cavernosus posteriorly from the sulcus cavernosus anteriorly. The sulcus cavernosus is formed by the pterygoid ventrolaterally and by the basisphenoid ventromedially. The nervi abducentis enters the canalis cavernosus dorsolateral to the foramen anterius canalis carotici cerebralis.

Canalis Nervus Facialis-The canalis nervus facialis (Fig. 3A-C) is located within the prootic and transmits the facial nerve (VII) from the ventral part of the fossa acustico-facialis to the dorsomedial part of the canalis cavernosus. The lateral part of the canalis nervus facialis is almost confluent with the dorsal part of the canalis pro ramo nervi vidiani.
Canalis Nervus Acustici-The canalis nervus acustici is formed by the prootic and transmits the acoustic nerve (VIII) from the fossa acustico-facialis to connect to the cavum labyrinthicum. The exit from the fossa acustico-facialis is located posterior to that of the facial nerve.

Canalis Basioccipitalis-The canalis basioccipitalis (Fig. 2D) are paired canals that emerge from the foramina basioccipitale on the ventral surface of the basioccipital-exoccipital complex. Within the bone, the canals converge and then fuse into a single canal within the basioccipital-exoccipital complex that extends dorsally and opens into the cavum cranii medially to the foramina nervi hypoglossi.

\section{DISCUSSION}

\section{Alpha Taxonomy}

Although the holotype of Eubaena cephalica (YPM 1785) is now lost, it was figured and illustrated independently by Hay $(1904,1908)$ and Gaffney $(1972 a, 1979)$ and it is therefore possible to evaluate its external morphology with ease. The skull of DMNH 96004 is more flattened, the maxillae are lower and less inflated, the triturating surfaces are less expanded, the dorsal exposure of the supraoccipital on the skull roof is larger, the jugal has a broader lateral exposure, and the parabasisphenoid is more elongated relative to the holotype. The midline scale that covers the frontal is more triangular, the parietal midline scale is triangular, not an elongated trapezoid, and the paired parietal scales form the anteromedial boundary of the upper temporal emargination in DMNH 96004 relative to the holotype. Because interspecific variation has never been discussed for the cranial scales of baenids and because the osteological differences are extremely minor, we attribute DMNH 96004 to Eubaena cephalica with confidence.

Given that the holotype is lost, it may seem prudent to designate DMNH 96004 as the neotype for Eubaena cephalica. The International Commission on Zoological Nomenclature (ICZN) requires, however, that neotypes only be designated if this helps alleviate a taxonomic problem (ICZN, 1999). Because the morphology of the lost holotype is well documented and the validity of Eubaena cephalica uncontroversial, we here conclude that the designation of a neotype is unwarranted.

\section{New Insights into the Internal and External Anatomy of Baenids}

With exception of the notable differences listed above, DMNH 96004 is similar to the holotype of Eubaena cephalica in its external anatomy. However, because this contribution provides the first description of the internal anatomy of a baenodd, we here discuss new insights into this mostly hidden anatomical region.

Opisthotic-The contribution of the opisthotic to the dorsal opening of the stapedio-temporal canal is routinely used to assess phylogenetic relationships within Paracryptodira, although a clear pattern is currently lacking that would reveal this character to have higher significance, because it is unevenly distributed across paracryptodires (see Lyson et al., 2016). We here confirm that Eubaena cephalica lacks a contribution of the opisthotic to the foramen stapedio-temporale but note that the CT scans reveal a contribution of the opisthotic to the stapediotemporal canal. This contradicts conventional wisdom that the stapedio-temporal canal is formed by the prootic and quadrate only (Gaffney, 1979). Future work will need to clarify if a contribution of the opisthotic to any aspect of the stapedio-temporal canal is generally present among paracryptodires or unique to DMNH 96004.

Basioccipital Canals-We here identify two canals (Figs. 1B, 2D) in DMNH 96004 that pierce the base of the basioccipitalexoccipital complex and merge within the skull before entering the cavum cranii. To ease discussion, we herein name these 

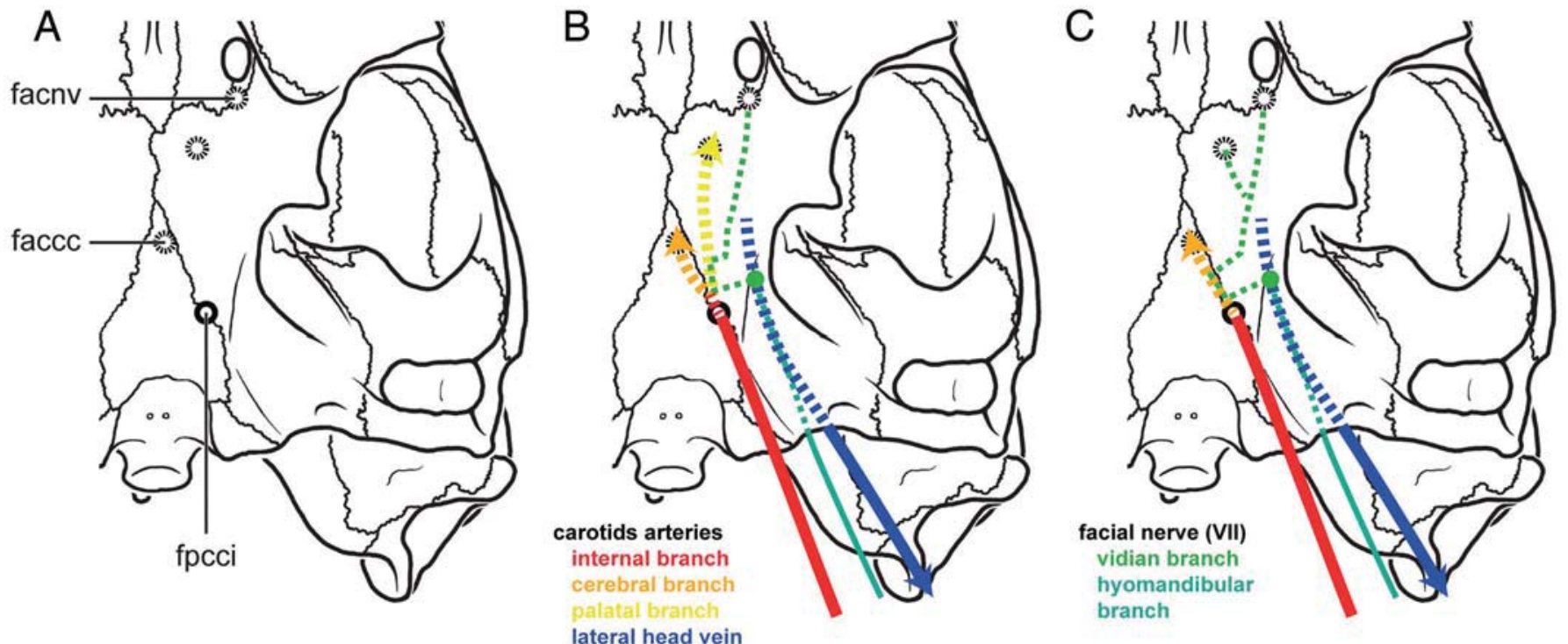

FIGURE 4. Simplified diagram highlighting differences between Gaffney (1982) and this study in the interpretation of the carotid canal system of Eubaena cephalica. A, select cranial foramina of Eubaena cephalica as observed by Gaffney (1982) and this study. B, path of the carotid arteries and facial nerves (VII) as hypothesized by Gaffney (1982) based on the observed cranial foramina. C, actual path of the carotid arteries and facial nerves (VII) as revealed by CT scans. Solid and dashed circles indicate foramina apparent in ventral and dorsal views, respectively. Abbreviations: facce, foramen anterius canalis carotici cerebralis; facnv, foramen anterius canalis nervi vidiani; fpcci, foramen posterius canalis carotici interni.

structures the foramina basioccipitale. Gaffney (1982) reported such foramina to be generally present among baenids, but he discussed neither their passage nor their possible function.

An examination of published figures confirms that paired foramina basioccipitale are widespread, but not persistent among baenids. Among non-baenodd taxa, CT scans of Arundelemys dardeni do not reveal any structures entering the ventral surface of the basioccipital (Lipka et al., 2006). Trinitichelys hiatti is known only from a single skull (Gaffney, 1972a), but neither the stereophotographs nor the restoration pictures allow us to recognize these foramina for this species. Partial skull material is available for Neurankylus lithographicus, but the relevant portion is not preserved (Larson et al., 2013). The available skull material of Neurankylus eximius is similarly incomplete, but neither pictures (Brinkman and Nicholls, 1993) nor CT volume renderings (Larson et al., 2013) show the structures in question. The only available skull of Neurankylus torrejonensis, by contrast, clearly exhibits two foramina on the ventral surface of the basioccipital (Lyson et al., 2016), although their passage is unclear. Hayemys latifrons is known from a partially crushed skull, but although neither the description of Hay (1908) nor the illustrations of Gaffney (1972a) provide evidence of foramina, personal observations of the skull show these structures.

Among baenodds, two skulls are known for the unresolved, basal taxon Arvinachelys goldeni, but these show no evidence for the presence of the foramina, likely due to crushing (Lively, 2015). Among the 11 species currently recognized as eubaenines, skulls are available for Baena arenosa, 'Baena' affinis, Stygiochelys estesi, Chisternon undatum, and Eubaena cephalica (Joyce and Lyson, 2015). We find no evidence for foramina in Baena arenosa and 'Baena' affinis (Hay, 1908; Gaffney, 1972a; Joyce and Lyson, 2015), but paired foramina are clearly present in Eubaena cephalica (Gaffney, 1972a; this study), Stygiochelys estesi, and Chisternon undatum (Gaffney and Hiatt, 1971; Gaffney, 1972a). Among palatobaenines, foramina can clearly be recognized for Peckemys brinkman (Lyson and Joyce, 2009b) and all three species of Palatobaena (Archibald and Hutchison, 1979; Lyson and Joyce, 2009a), but not in Cedrobaena putorius, Gamerabaena sonsalla, Goleremys mckennai, or Plesiobaena antiqua.
Our review reveals that paired foramina are common occurrences at the base of the basioccipital among baenids, but given that the skulls of turtles are pockmarked with small foramina of unknown function, it is possible that these foramina are more prevalent, but only rarely reported, either directly in text descriptions or indirectly by highlighting them in illustrations. Given that foramina basioccipitale appear to be systematically lacking in the outgroups, we suggest focusing on these structures in the future, because they may be useful in diagnosing a clade within Baenidae.

The Carotid and Facial Nerve Systems in Baenids-The newly reported absence of the palatine branch of the carotid artery in DMNH 96004 is surprising, because this canal and its associated foramina have been persistently discussed as being present in paracryptodires in the last decades (Gaffney, 1972a, 1982; Sterli et al., 2010; Rabi et al., 2013). We instead identify the canal exiting the internal carotid artery anterior to the canalis pro ramo nervi vidiani as the canalis nervus vidianus (Figs. 3, 4). In this section, we explain our rationale for this identification and compare the carotid circulation of DMNH 96004 with previous interpretations of the carotid circulation and vidian innervation in baenid turtles. Finally, we discuss the implications of this discovery for further work on the carotid circulation and basicranium of turtles. The nomenclature follows that of Gaffney (1972b), with notable updates from Rabi et al. (2013) for the carotid system and those for the vidian system proposed herein.

According to Albrecht (1967, 1976) and Gaffney (1972b, 1979), the canalis caroticus palatinum, when present, opens onto the floor of the sulcus cavernosus lateral to the rostrum basisphenoidale through the foramen anterius canalis carotici palatinum. In DMNH 96004, the canal that laterally branches from the canalis caroticus internus does not lead to the sulcus cavernosus but rather crosses the full length of the pterygoid to exit posterodorsomedially to the foramen palatinum posterius (Figs. 3, 4C). Siebenrock (1897), Soliman (1964), and Albrecht (1976) noted that the vidian nerve of modern turtles crosses the pterygoid through its own canal to reach the fossa orbitalis, and Gaffney (1982) observed a vidian canal in a fragmentary Baena sp. skull, posterior to the foramen palatinum posterius and passing through the palatine and the pterygoid. The canal exiting the 
internal carotid of DMNH 96004 therefore corresponds to the canalis nervus vidianus of other turtles, not to the canalis caroticus palatinum. We consequently identify the lateral canal in DMNH 96004 as the vidian canal and postulate the absence of the palatal canal. The absence of the palatal canal in Eubaena cephalica at first glance comes as a surprise, because the recent literature pertaining to the carotid system of turtles has focused on identifying the path of the cerebral and palatal branches in fossil and recent turtles (e.g., Gaffney, 1975; Jamniczky, 2008; Sterli et al., 2010; Rabi et al., 2013), and because Brinkman and Nicholls (1993) furthermore identified Gaffney's vidian canal (1982) as the canalis caroticus palatinum. However, a broad selection of turtles has previously already been reported to lack the palatine canal, including the majority of extant pleurodires (Albrecht, 1976) or Arundelemys dardeni, the only other paracryptodire for which CT scans are available (Lipka et al., 2006).

The cranial circulation and innervation pattern we reconstruct for Eubaena cephalica contradicts the pattern Gaffney (1982) established for Eubaena cephalica in particular and for baenids in general (Fig. 4B, C). Gaffney (1982:12) noted that the canalis caroticus palatinum "forms a groove continuous with the canalis caroticus internus and this groove extends anteriorly on the medial edge of the pterygoid until it exits at the foramen caroticum laterale." Gaffney (1982: fig. 5) furthermore highlighted in his reconstruction of baenid pterygoids the presence of the foramen posterius canalis carotici interni, the canalis pro ramo nervi vidiani, and a bifurcation between the canalis nervus vidianus and the canalis caroticus palatinum. As mentioned above, we are not able to identify a canalis caroticus palatinum in DMNH 96004 (Figs. 3B, 4C). Instead, the pterygoid of DMNH 96004 shows several anteroposteriorly arranged grooves of which the largest ends blindly within the basisphenoid ventrolaterally to the foramen anterius canalis carotici cerebralis. Although we cannot exclude the possibility that the material of Eubaena cephalica available to Gaffney (1982) indeed exhibits a canalis caroticus palatinum, we find it more plausible that he identified this groove to represent the open portions of this canal. Consistent with the reported presence of the canalis caroticus palatinum, Gaffney (1982) also reported the presence of the foramen anterius canalis carotici palatinum located towards the anterior along the suture between the palatine and the pterygoid (Figs. 3A, 4B), although we note that this opening is not actually connected to the purported canalis caroticus palatinum he identified. We can confirm the presence of this opening, but in DMNH 96004 it gives rise to a short canal that joins the primary canalis nervus vidianus close to the anterior end of the descending process of the parietal (Figs. 3, 4C). It is most likely that this canal is a branch of the canalis nervus vidianus, because a similar canal is observed in Sternotherus odoratus, the foramen arteriae anteriovidianae of Albrecht (1967).

\section{CONCLUSION}

We here describe a new skull of the baenid turtle Eubaena cephalica from the Upper Cretaceous (Maastrichtian) Hell Creek Formation of North Dakota that closely resembles the reported external anatomy of the now lost holotype of the species in all regards. Micro-CT scans of the new specimen provide the first detailed insights into the internal anatomy of a baenid turtle, but because few fossil and recent turtles have been CT-scanned to date, only a few comparative statements can be made. We here document for the first time an internal contribution of the opisthotic to the canalis stapedio-temporalis and the presence of paired canals within the basioccipital, the canalis foramen basioccipitale, that join within the bone to form a single canal of unknown function. More importantly, we here document that the new skull possesses a well-developed, branching canalis nervus vidianus but lacks a canalis caroticus palatinum, which contradicts the previously reported circulation and innervation pattern for Eubaena cephalica specifically and that of paracryptodires in general. Future investigation using CT scanning technology will be able to clarify if the pattern reported herein is unique to the new skull or representative of all paracryptodires. The latter conclusion is expected to have considerable implications for the systematics of fossil turtles.

\section{ACKNOWLEDGMENTS}

We thank T. Tucker for preparing the skull described herein. C. Foth hand-carried the specimen from the U.S.A. to Switzerland, C. Neururer aided with CT scanning, and V. Volpato provided assistance with the digital manipulation of CT data. Donald Brinkman and an anonymous reviewer made suggestions that improved the manuscript. This study was funded by a visiting student grant to Y. Rollot from the International Office of the University of Fribourg and by the Department of Geosciences of the University of Fribourg.

\section{ORCID}

Yann Rollot (D) http://orcid.org/0000-0002-2020-9456

Tyler R. Lyson (D) http://orcid.org/0000-0003-4391-9044

Walter G. Joyce (D) http://orcid.org/0000-0003-4726-2449

\section{LITERATURE CITED}

Albrecht, P. W. 1967. The cranial arteries and cranial arterial foramina of the turtle genera Chrysemys, Sternotherus, and Trionyx: a comparative study with analysis of possible evolutionary implications. Tulane Studies in Zoology 14:81-99.

Albrecht, P. W. 1976. The cranial arteries of turtles and their evolutionary significance. Journal of Morphology 149:159-182.

Archibald, J. D., and J. H. Hutchison. 1979. Revision of the genus Palatobaena (Testudines, Baenidae) with the description of a new species. Postilla 177:1-19.

Batsch, A. J. G. C. 1788. Versuch einer Anleitung, zur Kenntniß und Geschichte der Thiere und Mineralien. Akademische Buchhandlung, Jena, 528 pp.

Brinkman, D. B. 2003. Anatomy and systematics of Plesiobaena antiqua (Testudines: Baenidae) from the mid-Campanian Judith River Group of Alberta, Canada. Journal of Vertebrate Paleontology 23:146-155.

Brinkman, D. B., and E. L. Nicholls. 1991. Anatomy and relationships of the turtle Boremys pulchra (Testudines: Baenidae). Journal of Vertebrate Paleontology 11:302-315.

Brinkman, D. B., and E. L. Nicholls. 1993. The skull of Neurankylus eximius (Testudines: Baenidae) and a reinterpretation of the relationships of this taxon. Journal of Vertebrate Paleontology 13:273-281.

Cope, E. D. 1868. On some Cretaceous Reptilia. Proceedings of the Academy of Natural Sciences of Philadelphia 20:233-242.

Cope, E. D. 1873. Descriptions of some new Vertebrata from the Bridger Group of the Eocene. Proceedings of the American Philosophical Society 12:460-465.

Gaffney, E. S. 1972a. The systematics of the North American family Baenidae (Reptilia, Cryptodira). Bulletin of the American Museum of Natural History 147:241-320.

Gaffney, E. S. 1972b. An illustrated glossary of turtle skull nomenclature. American Museum Novitates 2486:1-33.

Gaffney, E. S. 1975. A phylogeny and classification of the higher categories of turtles. Bulletin of the American Museum of Natural History 155:387-436.

Gaffney, E. S. 1979. Comparative cranial morphology of recent and fossil turtles. Bulletin of the American Museum of Natural History 164:65-375.

Gaffney, E. S. 1982. Cranial morphology of the baenid turtles. American Museum Novitates 2737:1-22.

Gaffney, E. S., and R. Hiatt. 1971. A new baenid turtle from the Upper Cretaceous of Montana. American Museum Novitates 2443:1-9.

Hay, O. P. 1904. On some fossil turtles belonging to the Marsh collection in Yale University Museum. American Journal of Science 18:261-276.

Hay, O. P. 1908. The Fossil Turtles of North America. Carnegie Institution of Washington Publication 75, 568 pp. 
Hutchison, J. H. 2004. A new Eubaenine, Goleremys mckennai, gen. et sp. n., (Baenidae: Testudines) from the Paleocene of California. Bulletin of the Carnegie Museum of Natural History 36:91-96.

International Commission on Zoological Nomenclature. 1999. International Code of Zoological Nomenclature. International Trust for Zoological Nomenclature, London, $306 \mathrm{pp}$.

Jamniczky, H. A. 2008. Turtle carotid circulation: a character analysis case study. Biological Journal of the Linnean Society 93:239-256.

Joyce, W. G., and T. R. Lyson. 2015. A review of the fossil record of turtles of the clade Baenidae. Bulletin of the Peabody Museum of Natural History 56:147-183.

Larson, D. W., N. R. Longrich, D. C. Evans, and M. J. Ryan. 2013. A new species of Neurankylus from the Milk River Formation (Cretaceous: Santonian) of Alberta, Canada, and a revision of the type species N. eximius; pp. 389-405 in D. B. Brinkman, P. A. Holroyd, and J. D. Gardner (eds.), Morphology and Evolution of Turtles. Springer, Dordrecht, The Netherlands.

Leidy, J. 1870. [Descriptions of Emys jeanesi, Emys haydeni, Baena arenosa, and Saniwa ensidens]. Proceedings of the Academy of Natural Sciences of Philadelphia 1870:123-124.

Lipka, T. R., F. Therrien, D. B. Weishampel, H. A. Jamniczky, W. G. Joyce, M. W. Colbert, and D. B. Brinkman. 2006. A new turtle from the Arundel Clays (Potomac Formation, Early Cretaceous) of Maryland, USA. Journal of Vertebrate Paleontology 26:300-307.

Lively, J. R. 2015. A new species of baenid turtle from the Kaiparowits Formation (Upper Cretaceous: Campanian) of southern Utah. Journal of Vertebrate Paleontology 35. doi: 10.1080/ 02724634.2015.1009084

Lyson, T. R., and W. G. Joyce. 2009a. A new species of Palatobaena (Testudines: Baenidae) and a maximum parsimony and Bayesian phylogenetic analysis of Baenidae. Journal of Paleontology 83:457-470.

Lyson, T. R., and W. G. Joyce. 2009b. A revision of Plesiobaena (Testudines: Baenidae) and an assessment of baenid ecology across the K/T boundary. Journal of Paleontology 83:833-853.

Lyson, T. R., and W. G. Joyce. 2010. A new baenid turtle from the Upper Cretaceous (Maastrichtian) Hell Creek Formation of North Dakota and a preliminary taxonomic review of Cretaceous Baenidae. Journal of Vertebrate Paleontology 30:394-402.
Lyson, T. R., and W. G. Joyce. 2011. Cranial anatomy and phylogenetic placement of the enigmatic turtle Compsemys victa Leidy, 1856. Journal of Paleontology 85:789-801.

Lyson, T. R., W. G. Joyce, G. E. Knauss, and D. A. Pearson. 2011 Boremys (Testudines: Baenidae) from the Latest Cretaceous and Early Paleocene of North Dakota: an 11 million year range extension and an additional K/T survivor. Journal of Vertebrate Paleontology 31:729-737.

Lyson, T. R., W. G. Joyce, S. G. Lucas, and R. M. Sullivan. 2016. A new baenid turtle from the early Paleocene (Torrejonian) of New Mexico and a species-level phylogenetic analysis of Baenidae. Journal of Paleontology 90:305-316.

Owen, R. 1842. Report on British fossil reptiles. Part II. Report of the British Association for the Advancement of Science 11:60-204.

Rabi, M., C.-F. Zhou, O. Wings, S. Ge, and W. G. Joyce. 2013. A new xinjiangchelyid turtle from the Middle Jurassic of Xinjiang, China and the evolution of the basipterygoid process in Mesozoic turtles. BMC Evolutionary Biology 13:203.

Siebenrock, F. 1897. Das Kopfskelett der Schildkröten. Sitzungsberichte der Kaiserlichen Akademie der Wissenschaften, MathematischNaturwissenschaftliche Klasse 106:245-328.

Soliman, M. A. 1964. Die Kopfnerven der Schildkröten. Zeitschrift für wissenschaftliche Zoologie 169:216-312.

Sterli, J., and M. S. de la Fuente. 2013. New evidence from the Palaeocene of Patagonia (Argentina) on the evolution and palaeo-biogeography of Meiolaniformes (Testudinata, new taxon name). Journal of Systematic Palaeontology 11:835-852.

Sterli, J., J. Müller, J. Anquetin, and A. Hilger. 2010. The parabasisphenoid complex in Mesozoic turtles and the evolution of the testudinate basicranium. Canadian Journal of Earth Sciences 47:1337-1346.

Vitek, N. S. 2012. Giant fossil soft-shelled turtle of North America. Palaeontologia Electronica 15(1):13A. palaeo-electronica.org/ content/2012-issue-1-articles/210-giant-soft-shelled-turtles. 